\title{
EMPATHY AND BURNOUT SYNDROME IN THE PRACTICE OF EMERGENCY SERVICES - PILOT STUDY
}

\author{
Lukasz Czyzewski ${ }^{1-3}$, Grzegorz Moczulski ${ }^{4}$, Marek Kozluk ${ }^{4}$, Dariusz Daniluk ${ }^{4}$, Dawid Beczek ${ }^{4}$, \\ Artur Karpiarz ${ }^{4}$, Pawel Panasewicz ${ }^{4}$, Krzysztof Izdebski ${ }^{4}$, Dominik Czarnocki ${ }^{4}$, \\ Karol Tomaszewski ${ }^{4}$, Emilian Siemieniuk ${ }^{4}$, Adam Sobieski ${ }^{4}$, Jaroslaw Michalak ${ }^{4}$, \\ Damian Wereda ${ }^{4}$, Kamil Mielczarek ${ }^{4}$, Marcin Madziala ${ }^{5}$
}

${ }^{1}$ Department of Nephrology Nursing, Medical University of Warsaw, Poland ${ }^{2}$ Faculty of Health Sciences, Collegium Mazovia Innovative University, Siedlce, Poland ${ }^{3}$ Department of Anaesthesiology, Cardinal Wyszynski National Institute of Cardiology, Warsaw, Poland ${ }^{4}$ Student of Faculty of Health Sciences, Collegium Mazovia Innovative University, Siedlce, Poland ${ }^{5}$ Department of Emergency Medicine, Medical University of Warsaw, Poland

\begin{abstract}
INTRODUCTION: The burnout syndrome is a result of stress on the work situation and most often concerns professions requiring emotional and direct contact with another human being. The level of empathy is closely related to the phenomenon of occupational burnout. The aim of the study was to determine the impact of socio-demographic factors of emergency services employees on the level of empathy.

METHOD: In the period January-March 2018, a survey was conducted using a questionnaire - Emphatic Sensitiveness Scale (ESC) and an anonymous author's questionnaire containing questions regarding sex, age, length of employment, occupation, marital status and number of hours worked per month. The survey was addressed to 81 employees of emergency services: paramedics $(n=17)$ and firefighters $(n=23)$. The control group consisted of 16 nurses and 25 people performing non-medical professions.

RESULTS: The average number of hours worked per month by the respondents was $189 \pm 49$. There were 50 females (62\%) and 31 males (38\%). The questionnaire showed statistically significant differences in perspective taking domain between the control group composed of people working in non-medical professions ( $25.6 \pm 4.3)$ and emergency services professionals: firefighter $(28.7 \pm 3.6)$ vs. paramedic $(29.9 \pm 3.5)$ vs. nurse (31.2 \pm 3.0$)$, $p<0.001$. It has been shown a statistically significant effect of sex on personal distress domain: male $(21.4 \pm 4.2)$ vs. female $(24.3 \pm 4.7), p=0.005$.
\end{abstract}

CONCLUSIONS: In conclusion, our data indicates that: (1) Nurses were characterised by the highest level of empathy amongst the surveyed professional groups; (2) Females were characterised by a higher level of personal distress; (3) Variables such as sex, age, and length of employment did not affect the level of empathy.

KEY WORDS: empathy, paramedic, nurse, firefighter

Disaster Emerg Med J 2018; 3(1): 5-11

\section{INTRODUCTION}

The burnout syndrome is a result of stress on the work situation and most often concerns professions requiring emotional and direct contact with another human being. The burnout syndrome has been described in the medical literature for many years. Surveys prove conclusively that a larger scale of occupational burnout is observed in the group of 
nurses than it would be among other professions, especially medical ones. According to Maslach, the burnout syndrome is defined as a psychological syndrome of emotional exhaustion, depersonalisation and a reduced sense of personal achievement that may occur in people working with other people [1, 2].

In many research works, the nurses self-evaluated for the burnout syndrome, working in various wards. However, using the self-assessment questionnaire may result in the risk of a diagnosis of occupational burnout with such disorders as: depression, stress, chronic fatigue or neurosis. This is because in surveys, the somatic and mental burnout syndromes that may be symptoms of the above-mentioned disorders are often assessed. It should be noted that in contrast to stress or depression, neurobiological and psychobiological mechanisms of the emergence of physical and psychological symptoms of burnout are not fully understood. However, the analysed studies show that there is a relationship between burnout and depression, stress and burnout or chronic fatigue and burnout. According to Maslach, personality and demographic characteristics are secondary causes of the appearance of burnout syndrome, and in her opinion, those that are directly related to the work environment, i.e. physical and psychosocial factors of the professional environment, are more dangerous.

Previous research proves that the burnout syndrome can be observed slightly more often in younger people, what may be related to a painful confrontation of dreams and expectations with reality and lack of work experience. It cannot be ruled out (this is also confirmed by the authors of their research work based on their own observations), that burnt employees are more likely to leave their profession, and older workers, who have been able to develop adaptation mechanisms, remain.

The level of empathy is closely related to the phenomenon of occupational burnout. Empathy is a predictor of proper implementation of medical profession. Working with people and for people can be not only a source of satisfaction and satisfaction, but sometimes also a source of discouragement. It is assumed that a high level of empathy can protect against the onset of burnout syndrome.

The aim of the study was to determine the impact of socio-demographic factors of emergency services employees on the level of empathy.

\section{METHODS}

In the period January-March 2018, a survey was conducted using a questionnaire - Emphatic Sensitiveness Scale (ESC) [3] and an anonymous author's questionnaire containing questions regarding sex, age, length of employment, occupation, marital status and number of hours worked per month. The survey was addressed to 81 employees of emergency services: paramedics $(n=17)$ and firefighters $(n=23)$. The control group consisted of 16 nurses and 25 people performing non-medical professions.

The ESC questionnaire consists of $28 \mathrm{sin}$ gle-choice questions with a five-point scale of answers: from "I completely disagree" to "I strongly agree". The questionnaire contains three subscales: empathic concern (EC) (focused on other; compassionate) - the higher the score the respondent achieves on this scale, the higher his level of empathic concern; personal distress (PD) (taking over others' negative emotions) - the higher the test score is on this scale, the higher his level of personal annoyance; perspective taking (PT) - the higher the test score the respondent achieves on this scale, the higher his level of perspective adoption. The scale is characterised by satisfactory reliability and accuracy. The overall result of the questionnaire is calculated by summing the results from three subscales: EC, PD and PT.

\section{STATISTICAL ANALYSIS}

Results concerning quantitative variables were presented as average values \pm standard deviation. Qualitative variables (age, sex) were presented as quantity (n) and percentage values of the whole group (\%), while proportions in groups were assessed with a Chi-squared test. Statistica 13.1 software (StatSoft Inc., Tulsa, OK) was used in the statistical analysis. $p<0.05$ was adopted as the significance level.

\section{RESULTS}

The average number of hours worked per month by the respondents was $189 \pm 49$. The average length of the employment was $15 \pm 15$ years. There were 50 females (62\%) and 31 males (38\%). Sixty-three (78\%) of the respondents declared being married, $18(22 \%)$ of persons had the status of a single. The questionnaire showed statistically significant 
Table 1. Univariate comparison of study groups. Continuous data are presented as mean \pm SD

\begin{tabular}{|l|c|c|c|c|c|c|}
\hline \multicolumn{1}{|c|}{ Parameters } & Other & Firefighter & Paramedic & Nurse & All groups & $\mathbf{p}$ \\
\hline Working period, y & $11.9 \pm 8.4$ & $17.0 \pm 23.2$ & $17.6 \pm 10.0$ & $13.9 \pm 13.7$ & $14.9 \pm 15.2$ & 0.582 \\
\hline $\begin{array}{l}\text { Number of hours/ } \\
\text { month }\end{array}$ & $173 \pm 38^{*}$ & $184 \pm 21^{*}$ & $229 \pm 75$ & $176 \pm 38^{*}$ & $189 \pm 49$ & 0.001 \\
\hline Age, y & $38 \pm 10$ & $37 \pm 7$ & $44 \pm 10$ & $39 \pm 12$ & $39 \pm 10$ & 0.177 \\
\hline Emphatic concern & $31.7 \pm 5.6^{\# \star}$ & $34.0 \pm 4.7$ & $34.6 \pm 3.9$ & $37.1 \pm 4.5$ & $34.0 \pm 5.1$ & 0.009 \\
\hline Personal distress & $22.8 \pm 4.5$ & $21.0 \pm 4.0^{\#}$ & $21.5 \pm 3.8^{\#}$ & $25.4 \pm 5.2$ & $22.5 \pm 4.6$ & 0.015 \\
\hline Perspective taking & $25.6 \pm 4.3^{* \# \&}$ & $28.7 \pm 3.6$ & $29.9 \pm 3.5$ & $31.2 \pm 3.0$ & $28.5 \pm 4.2$ & $<0.001$ \\
\hline
\end{tabular}

${ }^{*} p<0.05$ at post-hoc analysis with a paramedic

${ }^{\#} \mathrm{p}<0.05$ at post-hoc analysis with a nurse

$\varepsilon_{p}<0.05$ at post-hoc analysis with a firefighter

differences between the control group composed of people working in non-medical professions and emergency services professionals - univariate comparison of study groups is presented in Table 1 and Figures $1-4$. It has been shown a statistically signif-

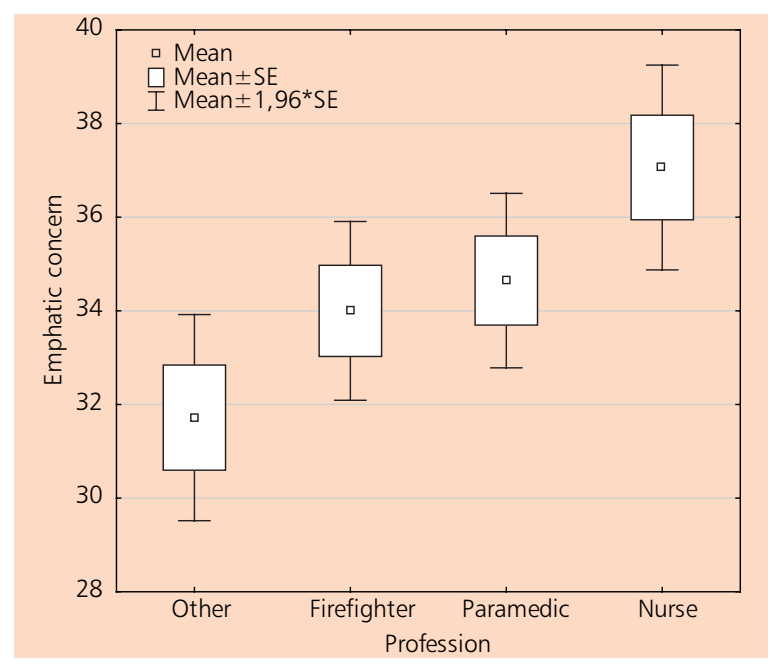

FIGURE 1. Emphatic concern according to profession

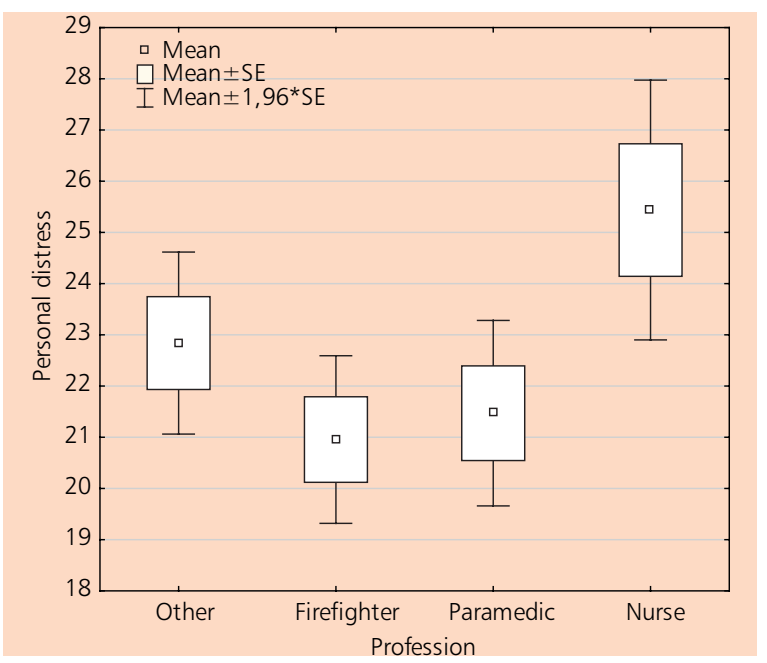

FIGURE 2. Personal distress according to profession icant effect of sex on personal distress - univariate comparison of study groups according to sex and marital status is presented in Tables 2, 3 and Figure 5 . Results of simple regression analyses between ESC domains are presented in Table 4.

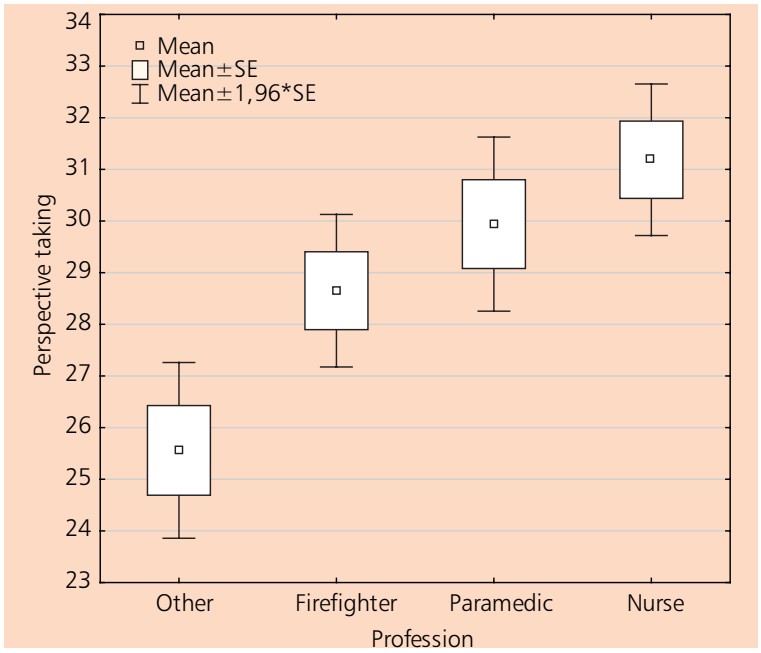

FIGURE 3. Perspective taking according to profession

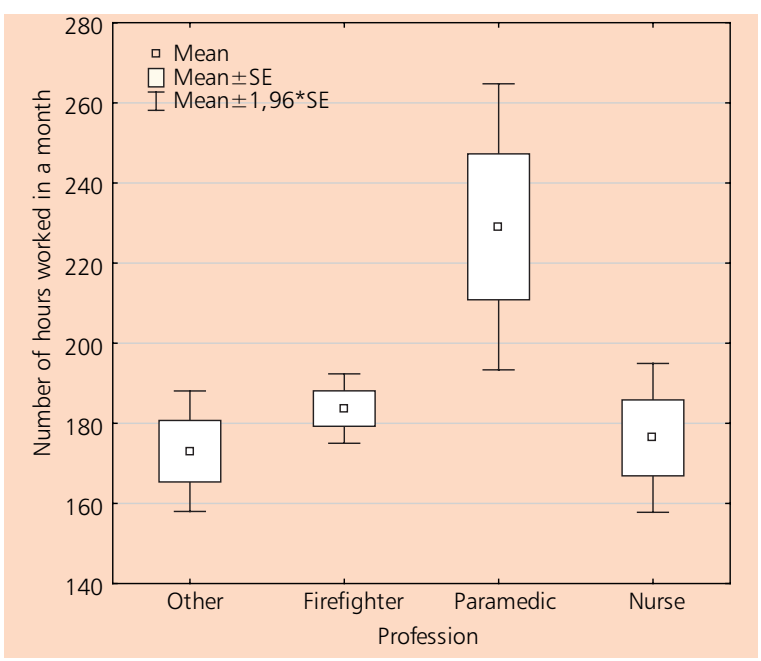

FIGURE 4. Number of hours worked in a month according to profession 


\begin{tabular}{|l|c|c|c|}
\hline \multicolumn{1}{|c|}{ Table 2. Univariate comparison of study groups according to sex. Continuous data are presented as mean \pm SD } \\
\hline Parameters & Male & Female & p \\
\hline Age & $40 \pm 9$ & $38 \pm 11$ & 0.527 \\
\hline Working period & $17 \pm 17$ & $12 \pm 11$ & 0.194 \\
\hline Number of hours/month & $200 \pm 56$ & $170 \pm 29$ & 0.007 \\
\hline Emphatic concern & $33.6 \pm 4.7$ & $34.7 \pm 5.7$ & 0.329 \\
\hline Personal distress & $21.4 \pm 4.2$ & $24.3 \pm 4.7$ & 0.005 \\
\hline Perspective taking & $28.3 \pm 4.2$ & $28.8 \pm 4.4$ & 0.577 \\
\hline
\end{tabular}

Table 3. Univariate comparison of study groups according to marital status. Continuous data are presented as mean \pm SD

\begin{tabular}{|l|c|c|c|}
\hline \multicolumn{1}{|c|}{ Parameters } & Marriage & Single & p \\
\hline Number of hours/month & $193.2 \pm 53.3$ & $172.1 \pm 25.7$ & 0.110 \\
\hline Emphatic concern & $33.5 \pm 5.0$ & $35.8 \pm 5.1$ & 0.089 \\
\hline Personal distress & $22.3 \pm 4.6$ & $23.3 \pm 4.5$ & 0.405 \\
\hline Perspective taking & $28.1 \pm 4.4$ & $29.7 \pm 3.3$ & 0.176 \\
\hline
\end{tabular}

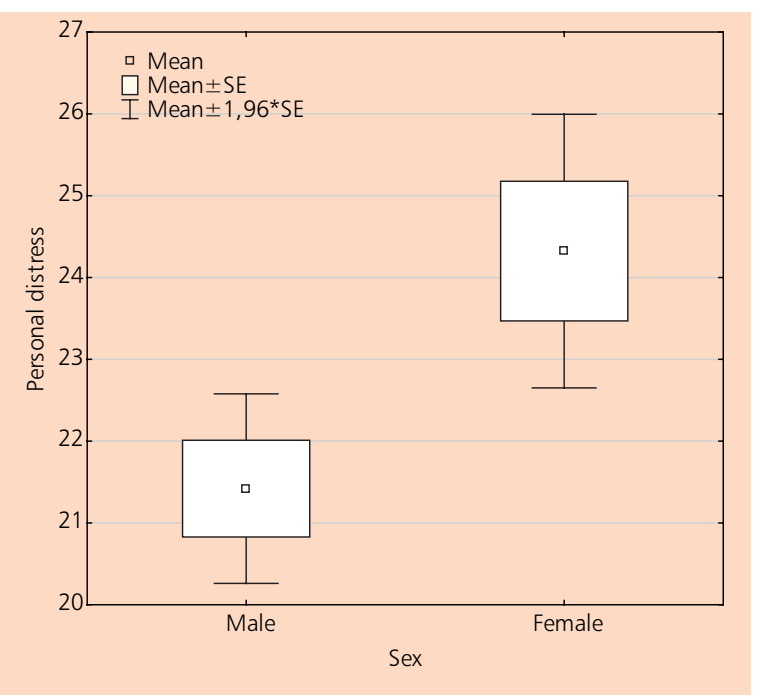

FIGURE 5. Personal distress according to sex

\section{DISCUSSION}

In the research, the authors show contradictory results regarding the relationship between occupation- al burnout and sex $[4,5]$. In the majority of cases, women show higher rates of emotional exhaustion and men show depersonalisation. Own research shows higher rates of occupational burnout in men, where they constitute a statistically larger group than women, who distance themselves and treat patients objectively. The authors' own research confirms the negative impact of shift work proved in the literature, which is a big burden affecting the quality of personal and professional life. Quoted studies have shown, that an irregular, 12-hour work system predisposes this syndrome and is even a stressful factor [6].

The researches among doctors and nurses of surgical wards of selected hospitals in Gdansk confirm, after Kaslov and Schuman [7], that the warning signs indicating the threatening burnout syndrome include: lack of willingness to work, reluctance to go out to work, negative attitudes towards patients, irritability, lack of patience and frequent diseases. Professional work, when it is satisfying, makes more

Table 4. Results of simple regression analyses between ESC domains

\begin{tabular}{|l|c|c|c|c|c|c|}
\hline \multirow{2}{*}{} & \multicolumn{2}{|c|}{ Emphatic concern } & \multicolumn{2}{c|}{ Personal distress } & \multicolumn{2}{c|}{ Perspective taking } \\
\cline { 2 - 7 } & $\mathbf{r}$ & $\mathbf{p}$ & $\mathbf{r}$ & $\mathbf{p}$ & $\mathbf{r}$ & $\mathbf{p}$ \\
\hline Age & 0.140 & 0.212 & 0.050 & 0.657 & -0.071 & 0.529 \\
\hline Working period & 0.120 & 0.285 & 0.052 & 0.643 & -0.092 & 0.412 \\
\hline Number of hours/month & -0.009 & 0.937 & 0.024 & 0.832 & -0.021 & 0.854 \\
\hline Emphatic concern & - & - & 0.347 & 0.001 & 0.408 & 0.000 \\
\hline Personal distress & 0.347 & 0.001 & - & - & 0.146 & 0.194 \\
\hline Perspective taking & 0.408 & 0.000 & 0.146 & 0.194 & - & - \\
\hline
\end{tabular}


sense, shapes the psyche, affects the development of personality and the general course of life.

In the study of Kowalczuk et al. [8], a group of 126 paramedics working in the Podlaskie Voivodeship was examined. The questionnaires were used for the assessment of the severity and type of aggression towards rescuers and the General State of Health of GHQ28. During the research, the conclusions were drawn that amongst rescuers working in the emergency room and in ambulance teams, the most common forms of aggression on the part of patients were: using raised voice tone $(95 \%)$, threats (85\%), attempted attacks and creating life or health emergencies (91\%).

It should be noted, that in Emergency Departments the most frequent form of aggression on the part of patients is the raised tone of voice. Seventy-two per cent of paramedics came across threats, $59 \%$ of the respondents had threatening situations and $44 \%$ of the respondents were exposed to attack. Therefore, based on the conducted research, it can be concluded that the most exposed to aggressive behaviour on the part of patients are rescuers working in outgoing teams and at the emergency room, than rescuers working in Emergency Departments.

In the study performed by Ogłodek et al. [9], stress and the severity of post-traumatic stress symptoms amongst paramedics were assessed. A group of 36 paramedics (18 men and 18 women) underwent a study. The average age in the group of subjects was 41 years. The respondents were people working at Emergency Departments. The research was based on a questionnaire assessing the intensity of post-traumatic stress - Mississippi-C PTSD Scale. The studies have shown significant relationships between the severity of post-traumatic stress symptoms in the study groups. The studied group of women perceived the atmosphere as difficult as $70 \%$ severe, $68 \%$ moderate and $60 \%$ mild of PTSD intensity. In contrast, the examined men rated the atmosphere as difficult in $80 \%$ with severe, $52 \%$ with moderate and $10 \%$ with mild intensity of PTSD. The activities of mental health prevention amongst paramedics aiming at minimising the risk of post-traumatic stress are very important.

In the study of Jałtuszewska et al. [10], the intensity of the stress level and ways of coping with stress in the group of professionally active paramedics and medical emergency students were assessed. The PSS-10 test was used to assess the stress level, while the CISS questionnaire was used to assess the ways of coping with stress. The respondent group consisted of 87 respondents, of whom there were 29 (33\%) paramedics working in the State Medical Rescue System, 29 (33\%) first-cycle students in the field of medical emergency services at the Pomeranian University in Slupsk, and 29 (33\%) students 2 of a summer study about the direction of medical emergency at the School of Adult and Youth Education. The average age in all groups was 30 years. Based on the research, it has been found that amongst the professionally active paramedics, the work experience has a significant impact on the stress level and on how to cope with stress. In half of the students, the low level of stress prevails, while in the half of paramedics the level is average, and in the majority of students the level of stress is high. It was found that students cope with stress in a manner focused on avoidance, while active rescuers professionally choose a task style.

Ogińska-Bulik et al. [11] studies on the sense of professional stress on a group of 100 firefighters from the State Fire Service from Lodz were presented. In the first stage, mean values of individual variables were analysed. Analysing the results of the research consisting in determining the scope of stress at work, self-efficacy and individual dimensions of occupational burnout, they depend on the age and seniority of the investigated officers. The obtained research results show that the average age of the tested firefighter group was $34 \pm 6$ years, while the average job seniority at the current position was $8 \pm 4$ years, and the average length of the internship was $13 \pm 6$ years. The level of stress at work (in total) was on average $112.52 \pm 24$, and the factors affecting this stress, i.e. the sense of mental workload, which is at the highest level, was $15.94 \pm 5.48$. The next factor from the most stressful is a sense of uncertainty caused by the organisation of work, which was $15.23 \pm 4.36$. The next factor, also very stressful, is the lack of awards at work $14.64 \pm 5.45$, and another factor at a high level is the sense of danger $10.86 \pm 2.86$. Factors that obtained lower average were social contacts $9.85 \pm 2.61$, responsibility $8.98 \pm 2.69$, physical nuisance $7.99 \pm 2.48$, no control $7.78 \pm 1.78$, unpleasant conditions $5.96 \pm 2.51$, and no support $4.37 \pm 1.62$. An important role in the surveyed group of firemen had a sense of self-efficacy, where the average was as much as $30.61 \pm 5.06$, and a sense of personal achievement $23.49 \pm 10.46$. Emotional exhaustion $8.36 \pm 6.39$ and depersonalisation $3.55 \pm 4.30$ is 
no longer so important. Next, the coefficients of correlation between age, seniority, sense of effectiveness and individual dimensions of occupational burnout were analysed. The presented analysis results indicate the highest correlation coefficient (0.20) between physical nuisance and emotional exhaustion, while the lowest correlation coefficient occurs between the sense of effectiveness and emotional exhaustion. The subsequent analyses present the average values of individual dimensions of occupational burnout, depending on the level of perceived stress at work and its factors, and on the level of own effectiveness in people with low and high levels of stress. In summary, firefighters are in the group of people with lower severity of occupational burnout compared to other occupations, in which close contact with people plays an important role. It was noted that the level of stress in firefighters is not continuous or permanent compared to other professional groups. In the surveyed group of firemen, it was noted that if the sense of self-efficacy increases, emotional exhaustion decreases. The authors of the article believe that firefighters cope effectively with a high level of noticeable occupational stress, presume that they may also have personal resources to protect against burnout syndrome, but further research is required to determine this.

In the Schroeder's study [12] on the subject of a leader in the fire service, the author showed, that a leader from the point of view of psychology is a person, who primarily has personal authority or prestige. In addition, a leader is an influential person, thanks to what he can perform certain social roles. In addition, he occupies an important position in significant private or public organisations functioning in society and enjoys them in authority or official prestige. According to the author of the article, a leader is an exceptional person, extraordinary, possessing special abilities and distinguished by extraordinary character traits. Of all of them, special attention should be paid to four important traits. The first is the ability to positive, optimistic interpretation of unpleasant events, the ability to draw from them substantive, instructive conclusions. A leader also has a predisposition to influence others, inducing them to find a meaning even in the most unfavourable situations that can happen in a person's life. The leader's long feature is the particular gift of persuasion and another ethical integrity. It should be noted, however, that the most important skill is the ability to adapt, which should be understood as a special talent based on the ability to turn adversity into their own advantage, drawing strength and energy from them. This feature can be divided into two main advantages, such as the ability to capture the context of events and a very strong steadfastness. In order for leaders to function well in their social group, they must first of all have contact with people around them, which depends on many different factors, for example the ability to look at the situation from a certain perspective and how people will receive a certain gesture or behaviour. All these qualities and skills make leaders even more devoted to what they do, work with greater dedication and commitment.

\section{CONCLUSION}

Our data indicates that: (1) Nurses were characterised by the highest level of empathy amongst the surveyed professional groups; (2) Females were characterised by a higher level of personal distress; (3) Variables such as: sex, age, and length of employment did not affect the level of empathy.

Conflict of interest: The authors declare that they have no conflicts of interests. None of the authors involved in this study have any financial relationship.

Source of support: No sources of financial and material support to be declared.

Name of the department and institution in which the work was done: Faculty of Health Sciences, Collegium Mazovia Innovative University, Siedlce, Poland.

\section{REFERENCES}

1. Greenglass ER, Burke RJ, Fiksenbaum L. Workload and burnout in nurses. Journal of Community \& Applied Social Psychology. 2001; 11(3): 211-215, doi: 10.1002/casp.614.

2. Leiter MP, Harvie PL. Burnout among mental health workers: a review and a research agenda. Int J Soc Psychiatry. 1996; 42(2): 90-101, doi: 10.1177/002076409604200203, indexed in Pubmed: 8811393.

3. Kaźmierczak M, Plopa M, Retowski S. Empathic Sensitiveness Scale. Przegląd Psychologiczny. 2007; 50: 9-24.

4. Hallsten L, Josephson M, Torgen M. Performance - Based Self Esteem: A Driving Force in Burnout Processes and Its Assessment. National Institute for Working Life, Stockholm 2005.

5. Maslach C, Schaufeli WB, Leiter MP. Job burnout. Annu Rev Psychol. 2001; 52: 397-422, doi: 10.1146/annurev.psych.52.1.397, indexed in Pubmed: 11148311. 
6. Pokorski J, Ogińska H, Pokorska J, Hasselhorn HM. Praca zmianowa w pielęgniarstwie i jej postrzegana uciążliwość. In: Pokorski J, Ogińska H, Pokorska J, Hasselhorn HM. ed. Pielęgniarek polskich portret własny z Europą w tle, czyli raport z badań europejskich projektu NEXT. Naczelna Rada Pielęgniarek i Położnych, CIOP, materiały konferencyjne, Warszawa 2005.

7. Fengler J. Pomaganie męczy. Wypalenie w pracy zawodowej. GWP, Gdańsk 2001: 90-94.

8. Kowalczuk K, Jankowiak B, Krajewska-Kułak E, et al. [Exposure of medical rescuers to aggression at the workplace]. Ann Acad Med Stetin. 2009; 55(3): 76-80, indexed in Pubmed: 20698183.
9. Ogłodek E. Symptoms intensification of post-traumatic stress in individuals performing the job of a medical rescue worker. Environmental Medicine. 2011; 14(3).

10. Nowakowska K, Jabłkowska-Górecka K, Borkowska A. Coping styles and burning out syndrome in the emergency medicine students and emergency medicine students working as emergency workers. Psychiatr Psychol Klin. 2009; 9(4): 242-248.

11. Ogińska-Bulik M, Kaflik-Pieróg N. Occupational stress, self-efficacy belief and burnout syndrome in fire-fighters. Folia Psychologica. 2003; 7:37-47.

12. Schroeder M. Lider w straży. Organizacja i zarządzanie strategiczne. 2008. 